\title{
PASSAGENS E IMAGENS DO ATELIÊ DE PAULO BRUSCKY VISTOS ATRAVÉS DA CONTEMPORANEIDADE DA BIENAL
}

\section{PASSAGES AND THE ATELIER IMAGES OF PAUL BRUSCKY VISA ACROSS THE CONTEMPORARY BIENNIAL'S}

\section{Gildenir Carolino Santos}

\section{INTRODUÇÃO}

Pensar em Bienal leva-nos a imaginar trajetos e várias ações voltadas para a organização e exposição de objetos e instrumentos que serão vistos por várias pessoas em determinado período.

Nessas exposições vale também apresentar não somente objetos, mas locais, casas, edificações e até mesmo ateliê de arte em sua estrutura e posição original, que é o caso do ateliê apresentado neste ensaio sobre Paulo Bruscky.

Será apresentar neste ensaio, uma descrição dos locais, ou melhor, dizer, partes da casa doa artista, trazida de Recife (PE) para ser mostrada ao público o seu trabalho e como ele é organizado em várias perspectivas.

Antes, porém, deve-se apresentar uma breve conceituação sobre o que é um ateliê, na perspectiva da arte e cultura.

A etimologia da palavra "ateliê" é de origem francesa, e segundo o dicionário Houaiss da Língua Portuguesa (2001), ateliê quer dizer: “local onde os artesãos ou operários trabalham em conjunto, numa mesma obra ou para um mesmo individuo” [...] pode também ser oficina. Ainda no dicionário, menciona a definição de "local preparado para a execução de trabalhos de arte, fotografia ou mesmo estúdio”.

Em certos autores, podemos encontrar tais definições diferentes da apresentada, mas a essência é a mesma na valorização de local para trabalho sobre uma determinada arte. 


\section{A CONTEXTUALIZAÇÃO DE UM ATELIÊ : IMAGEM E FOTOGRAFIA}

O ambiente de um ateliê, não é só visto com um lugar apenas para instalação de objetos e outros instrumentos artísticos, mas também com um ambiente que proporciona visualizar imagens sobre objetos e desses objetos estipular uma maneira de descreve-los através de fotografias, gravuras ou principalmente pinturas retratadas em telas.

Fazendo essa abordagem entre os artistas sobre a realidade de um ateliê, é possível destacar palavras de alguns deles, afirmando que mantem um convívio intenso e com assiduidade aos seus ateliês, onde passam a maior parte de seu tempo, esboçando ou retratando uma arte, mesmo que dela seja a arte de fotografar. (GENET, 2001).

Ao mesmo tempo em que o trabalho de descrição do ateliê de Paulo Bruscky foi comentado, pode-se ter também o momento fotográfico do lugar (ateliê), em formato digital e desse formato apresentado por fotografias, observa-se maiores detalhes através das imagens referente à atenção visual do campo observado.

Esse momento também pode ser considerado como uma cenografia teatral, onde os personagens se movimentam e o cenário permanece intacto, mudando apenas quando acontece uma nova cena.

Segundo Aumont (1995, p.229), se tem como noção de cenografia teatral, no seu amplo sentido, a compreensão da representação dos lugares e até incluindo as relações entre personagens e arquitetura do ambiente descrito.

Como foi fotografado o ambiente do ateliê, e da fotografia iniciou-se a descrição propriamente dita, através das palavras de Fabris (2004, p.49), a autora comenta que:

[...] O retrato fotográfico, finalmente, proporciona um registro perfeito e fiel, longe de toda caricatura e das imprecisões da descrição verbal: (...) a imagem fala por si, com uma precisão notável e indica o exato ponto alcançado na infelicidade entre a primeira sensação e seu patamar mais elevado. 


\section{INÍCIO DE UMA VISITA: ESCOLHA DE UM OBJETO}

Durante a visita na Bienal de São Paulo, a tarefa foi escolher um objeto e descrevê-lo sob nossa ótica de meros catalisadores de informações do mundo contemporâneo.

Visitei vários objetos, obras de arte, trabalhos audiovisuais, pinturas de diversos autores de nacionalidades diferentes, além de pinturas alarmantes e que protestavam sobre alguma coisa no espaço e tempo.

Entre todo esse mundo de arte e cultura, escolhi como objeto para meu ensaio, o ateliê do artista pernambucano Paulo Bruscky, que vive em Recife.

Pode-se dizer que o ateliê de um artista, além de se constituir em seu espaço de trabalho, revela a intimidade de seu processo de criação.

No caso de Paulo Bruscky, seu ateliê também cumpre o papel de formação e de troca de idéias com outros artistas.

Quando falo no título deste ensaio sobre “descrição comparada”, quero dizer que irei comentar sobre o ateliê de Paulo Bruscky que tem algo comum com a profissão que exerço cuidando de uma biblioteca.

\section{OBSERVANDO O QUE SE PASSA NO ATELIÊ}

No ateliê de Paulo, observei nas salas expostas, objetos e materiais que mantém a mesma originalidade na sua casa em Pernambuco, além da projeção da casa com seus cômodos totalmente copiados do original, que retratavam o quotidiano de sua arte e transmite a sensação de poder observar além do muro, como um espectador fascinado com os detalhes e arrumações (digo em algumas salas) semelhantes ao interior de sua casa no Recife (PE). 


\section{Entrando no ateliê: a estante de livros}

Passando pela primeira sala, verifiquei uma estante de madeira alojada na parede, lotada de livros, tendo uns organizados em suas prateleiras e outros empilhados sobre o topo dos demais livros organizados. Acredito que ali seria montado o seu escritório, pois tinham os detalhes arrumados por luminárias e bibelôs destacados em alguns cantos das prateleiras.

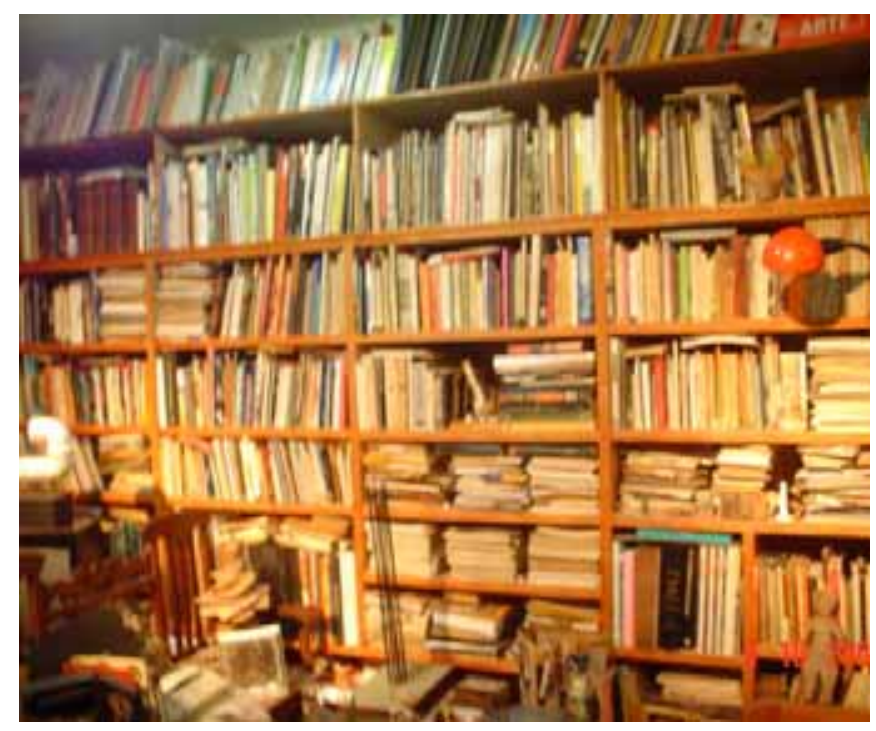

\section{A janela indiscreta}

Em outra sala, nota-se a organização nos mínimos detalhes como a janela que tinha em sua solera pequenos objetos e o pôster colocado no espaço da janela que parecia com os vitrôs aberto semelhante aos vitrôs reais que se apresentam pelos detalhes neste pôster que imitava uma janela aberta mostrando a realidade do lado de fora que não existia, ou

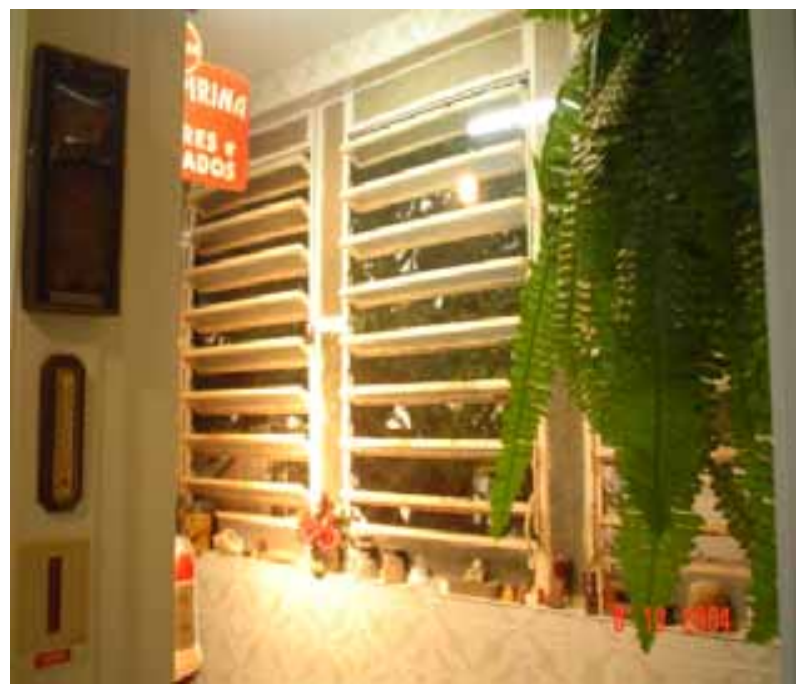
seja, uma natureza morta. Isto foi o que vi! 


\section{Comparando o calor de Recife}

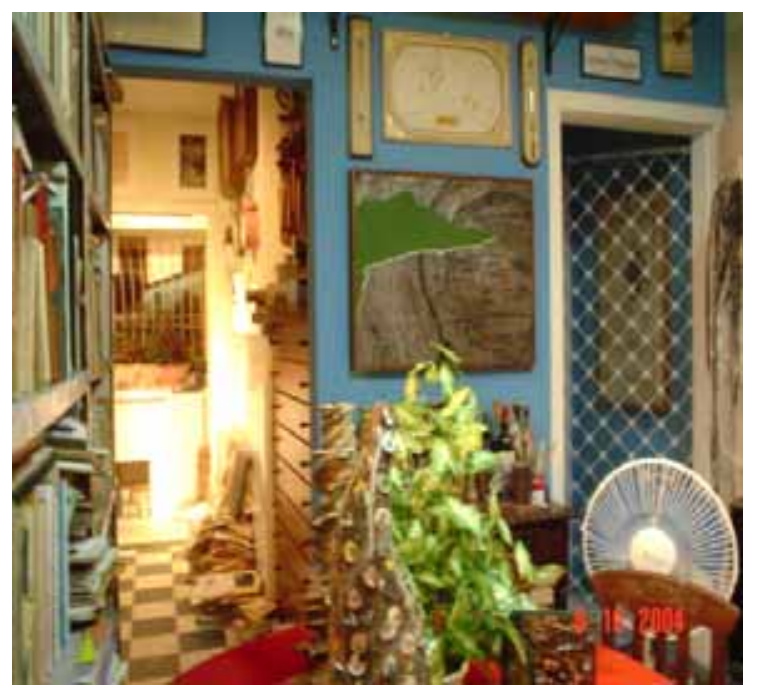

Na sala ao lado, observa-se uma arrumação caseira, onde os objetos estão dispostos organizadamente com quadros na parede, plantas postas sobre a mesa além de um ventilador que aparentemente está colocado ali, para amenizar o calor que se pode imaginar que acontece no Recife (PE).

\section{As caixas de remédios: um quadro diferente}

Outro lugar interessante na casa/ateliê do artista é um quadro na parede montado com apenas caixas de medicamentos. Colados uns ao lado dos outros, onde se pode observar que diminui o tamanho das caixas, à medida que estão organizadas da maior para a menor, e sorteadamente, é colocada uma caixa maior no meio deste quadro, assemelhando-se essa obra a uma cidade emparedada com vários

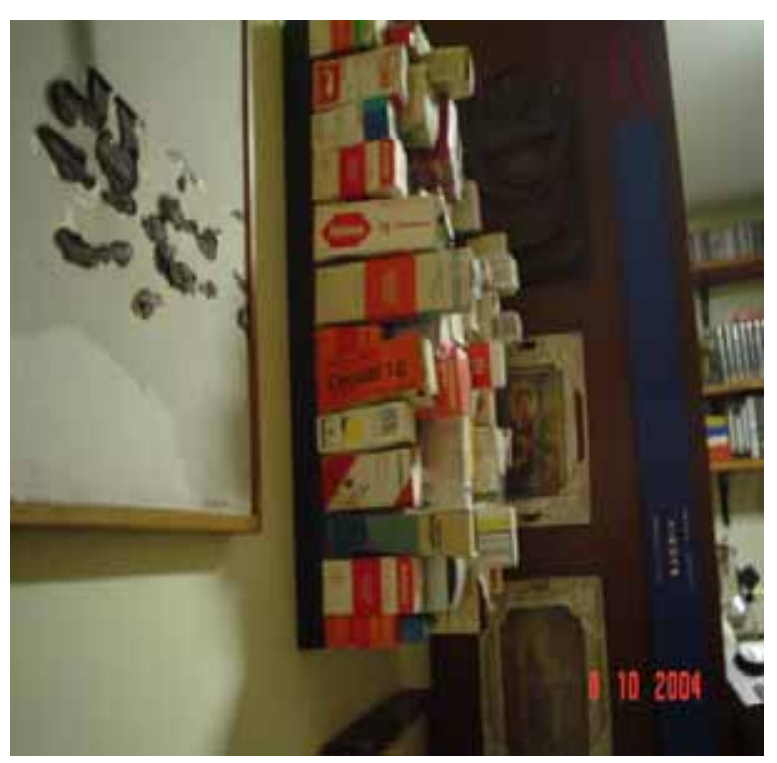
edifícios. 


\section{Sob a luz do dia}

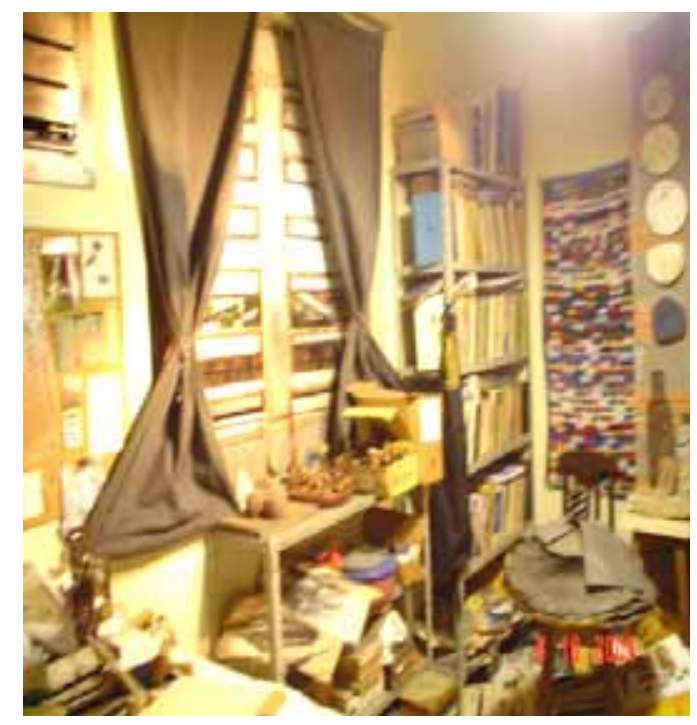

\section{Entre os pincéis e os quadros}

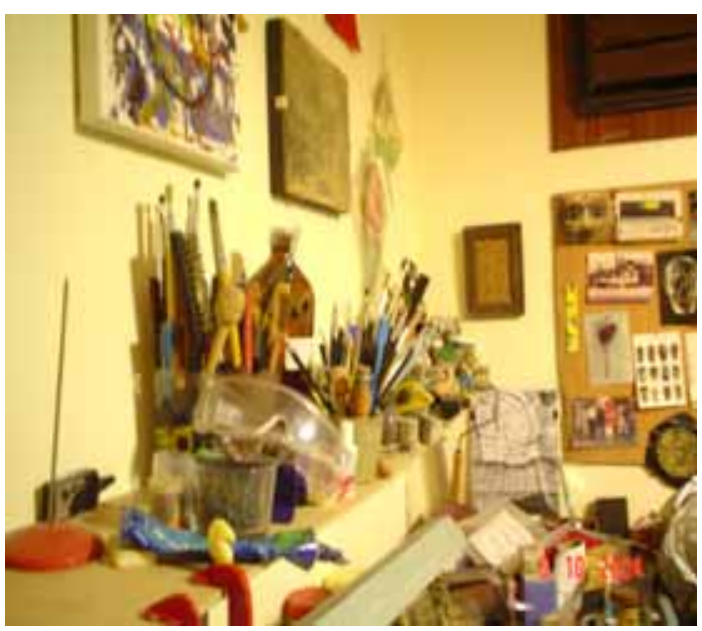

Novamente em outra sala é apresentada uma organização, comprometida ao mesmo tempo por documentos empilhados numa pequena estante, e ao lado dela, uma estante maior com livros (aparentemente não catalogados) organizados pelo mesmo tamanho. Alguns objetos são espalhados no chão, e a sensação quando se olha a janela onde está a pequena estante, é que o dia de sol destacado ali, mostra um realismo na ambientação desta sala.

A quantidade de objetos como pincéis, tintas, óculos são organizados numa bancada e nota-se que aquele arranjo na bancada faz parte do ambiente, além dos quadros diferentes pintado e colados com outros objetos diversos. 


\section{A arte da lata}

Observei também na cozinha, um quadro com palavras e objetos (latas de óleo) que formava uma frase bastante criativa, referente às latas de óleos: “quadro a óleo (colada à lata de óleo Salada) $100 \%$ puro (colada à lata de óleo Mazola) 100\% refinado. Finíssimo óleo comestível, nutritivo”.

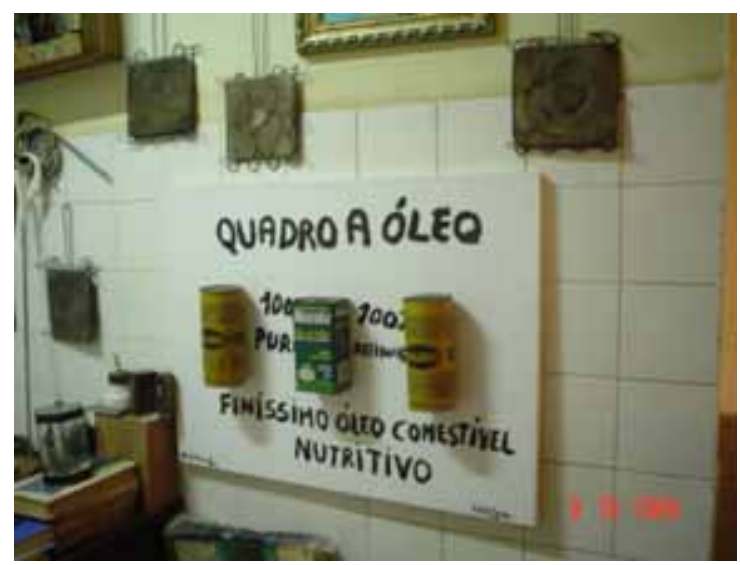

\section{As garrafas}

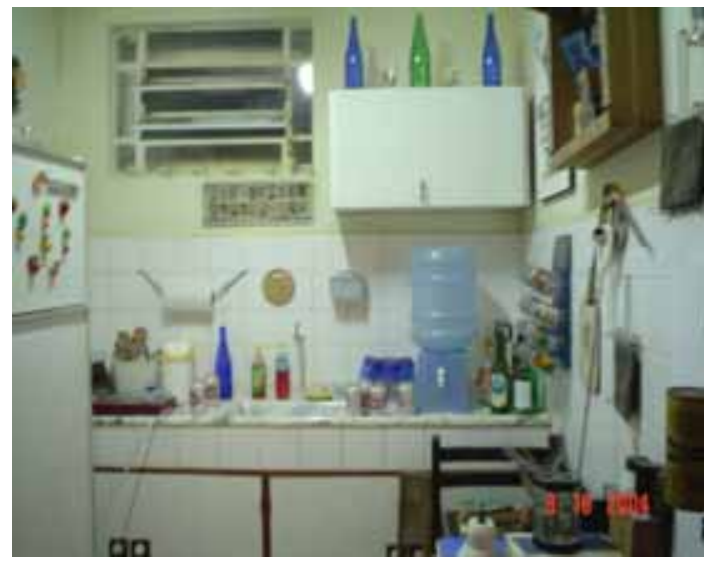

Ainda na cozinha, podia notar-se os utensílios colocados sobre a pia e a mesa, além de serem observadas a organização de garrafas iguais colocadas sobre o armário. 
Próximo à cozinha encontrava-se a área de serviço, que possuía em uma das paredes pilhas e pilhas de papéis colocados uns em cima dos outros. Acredito que estes documentos (papéis) façam parte da documentação exposta nas salas anteriores, e como não era possível acomodá-los no mesmo local foram divididos e guardados neste espaço na área de serviço. Reparando em todo ateliê, concluí-se tudo tem relevância para o artista, mesmo sendo objetos e documentos antigos, estes têm um significado muito importante para o artista.

\section{As caixas de papelão}

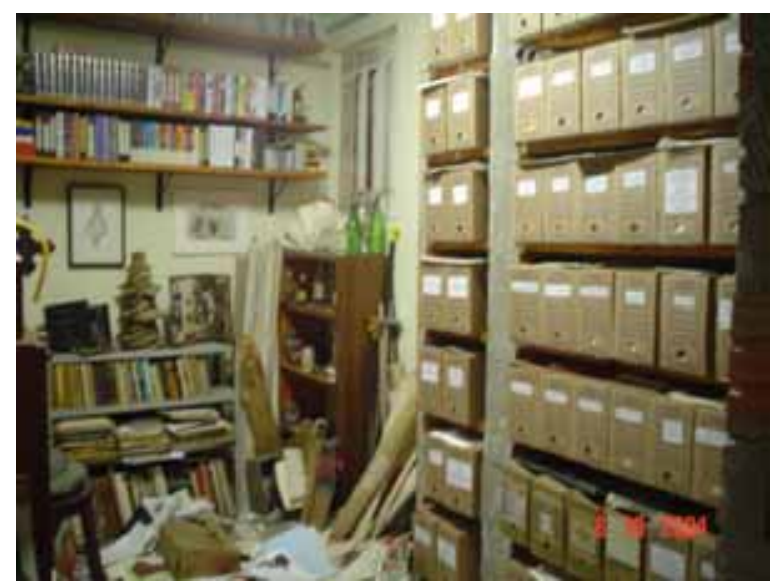

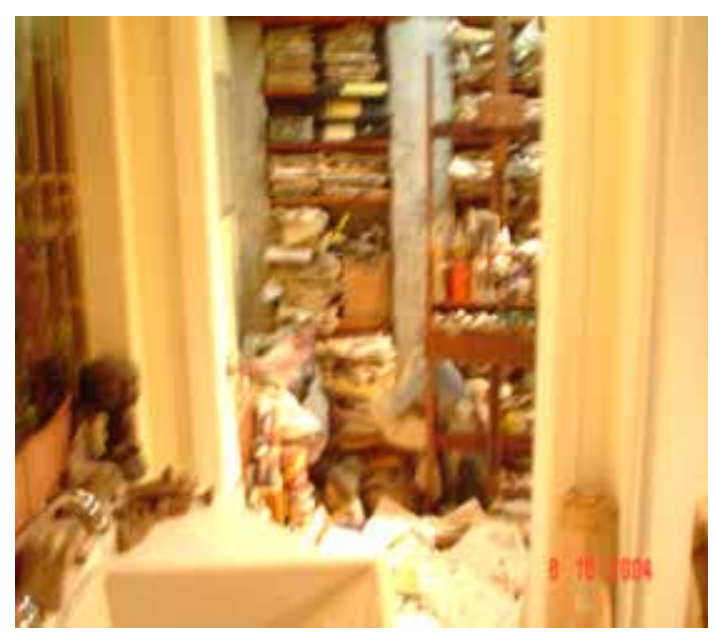

Parecia proposital, mas em uma das salas encontrava-se documentos (papéis) espalhados no chão e outros documentos estavam encostados nas proximidades da estante. Em uma das paredes possuía organizadamente, caixas de papelão colocadas em ordem alfabéticas de países, acredita-se que eram as correspondências que o artista possuía guardadas nas caixas, de acordo com a reportagem feita sobre o ateliê em matéria do jornal. Na parede também podia se encontrar em ordem, fitas de vídeos de filmes em prateleiras à francesa. 


\section{Bagunça ou arte?}

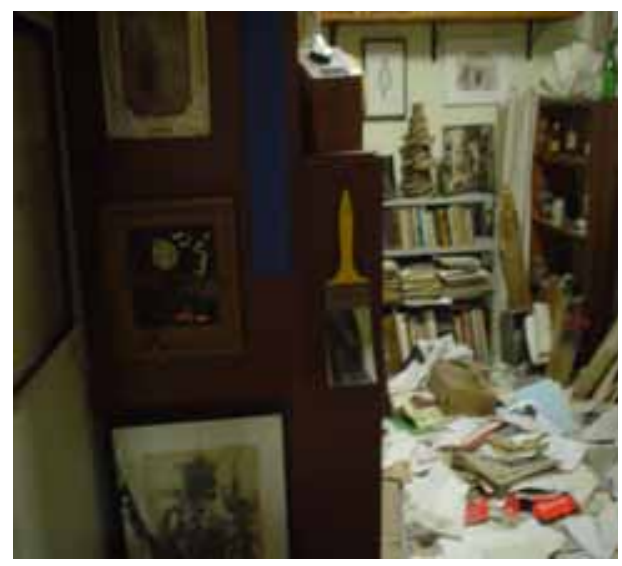

Um pouco mais à frente da sala anterior, o impacto com a quantidade de papéis espalhados no chão, assustava logo que via a sala e impressionava passando a sensação de

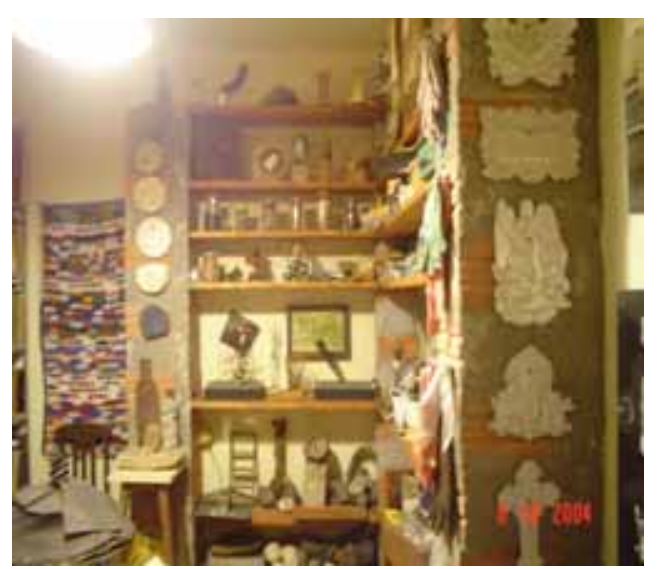
provocação e desordem para quem estava vendo aquela bagunça ali exposta, mas o contraste se mantinha pela arrumação de outros objetos em alguns pontos daquela sala.

Ao mesmo tempo em que se via os objetos espalhados, pode-se contemplar com a sala ao lado da anterior, onde os objetos estavam todos em ordem, objetos típicos do Pernambuco feitos à mão. Na sala seguinte, tinha uma parede com diversos relógios (parede e pulso) ornamentando o ambiente como objetos de decoração.

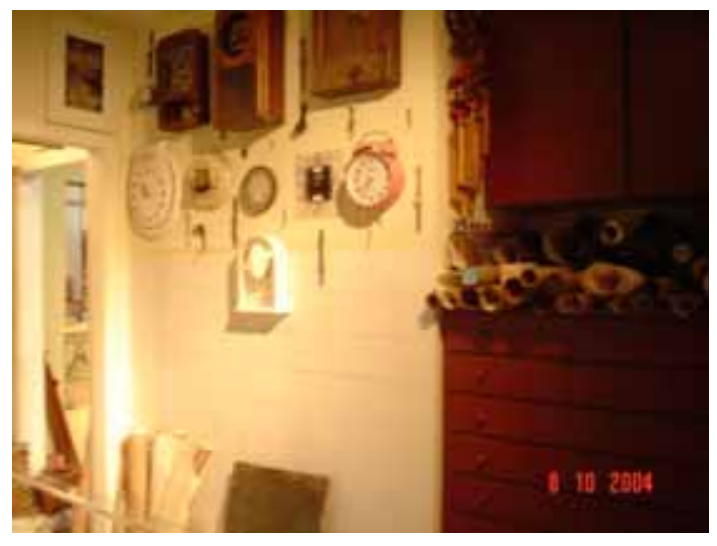




\section{CONSIDERAÇÕES FINAIS}

Conclui-se que em todo o momento, o artista nos traz uma mensagem com os objetos organizados ou em desordem ao mesmo tempo, ao apresentar o seu ateliê para visitação pública. Em alguns pontos pode-se observar comparando com o que exerço no cotidiano, os elementos chave da minha profissão: a organização dos livros, das fitas, dos documentos e outros objetos, que são tratados em uma biblioteca.

A biblioteca do artista podia ser vista em todas as salas, não se mantendo em uma única sala, desde a sala principal até a cozinha.

O artista consagra o seu ambiente de trabalho tentando passa ao espectador mensagens diferenciadas em cada sala que é visita, e também podemos comparar que ao trazer o ateliê para a 26a Bienal de São Paulo, o artista Paulo Bruscky divide com o espectador um acervo de correspondência elaborado ao longo de anos, que muito se assemelha ao arquivo da própria Bienal de São Paulo, suas caixa-arquivo são classificadas por país, conforme citado anteriormente. Assim, o ateliê reflete a dinâmica mesmo da produção contemporânea.

Outro ponto importante neste ensaio, é apresentar que a imagem que vimos pessoalmente, diferencia-se da imagem retratada nas fotografias digitais, que através delas consegue-se abstrair mais informações do que propriamente visitante cada ambiente.

\section{REFERÊNCIAS}

AUMONT, J. A imagem. 2.ed. Campinas: Papirus, 1995.

FABRIS, A. Identidades virtuais: uma leitura do retrato fotográfico. Belo Horizonte: Ed. UFMG, 2004.

HOUAISS, A. Dicionário Houaiss da língua portuguesa. Rio de Janeiro: Objetiva, 2001. 
